\title{
A REVIEW ON STRESS ANALYSIS AND WEIGHT REDUCTION OF AUTOMOBILE CHASSIS
}

\author{
Aditya V Sahasrabudhe ${ }^{1}$, Rajesh V Patil ${ }^{2}$ \\ ${ }^{\text {I}}$ Pursuing M.E, Mechanical Engineering Department, Sinhgad Institute of Technology and Science, Maharashtra, \\ India \\ ${ }^{2}$ Assistant Professor, Mechanical Engineering Department, Sinhgad Institute of Technology and Science, \\ Maharashtra, India
}

\begin{abstract}
Chassis is the term used to define the basic structure of the vehicle. It is also referred to as carrying unit as all the units including body are mounted on it. There are various loads acting on the chassis like inertia loads, static loads, over loads, etc. also it has to withstand the forces induced due to sudden braking and acceleration. In this paper a review has been made on the stress analysis of chassis by finite element analysis software packages like ANSYS, HyperWorks, etc. Weight reduction is gaining importance as the designers are trying to reduce the excess weight form the existing vehicle design. A review of the various techniques for weight reduction for the chassis is presented.
\end{abstract}

Keywords: chassis, finite element analysis, weight reduction, ANSYS

\section{INTRODUCTION}

The basic structure or the frame of the vehicle is called as chassis. In a vehicle, chassis is the part of the vehicle without body. All the important systems of the vehicle like engine, transmissions, brake, axles, suspensions, etc. are mounted on the chassis. Chassis can also be termed as carrying unit as it provides for the mounting of all units including body. Hence, the chassis can be referred to as the backbone of the vehicle. [14]

Various loads acting on the chassis are:

- Loads induced due to broken patch termed as short duration loads,

- Cornering loads when vehicle takes a turn,

- Impact loads due to collision of vehicle,

- Loads induced due to acceleration and braking termed as inertia loads

- Loads due to overload condition considered beyond vehicle capacity.

Structural analysis of the chassis can be performed by finite element analysis method. Normally software packages used for the analysis are HyperWorks, ANSYS, NASTRAN, etc.

Weight reduction is given a high priority across automotive industry today. It has become imperative for auto manufacturers to create designs that minimize weight of the vehicle. Modern methods of chassis design focus on weight reduction by removal of the additional weight. New and innovative ways are being studied and searched for reduction in weight of the existing vehicle design complying with industrial standards.
Various types of finite element analysis like linear static analysis, non-linear analysis, dynamic analysis, fatigue analysis, optimization analysis, crash analysis, etc. can be performed to assess the stress values of the chassis. [15]

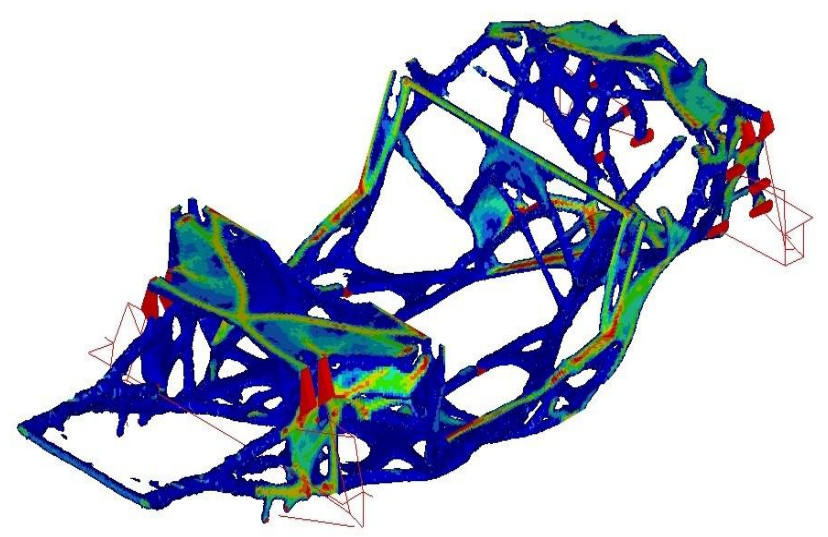

Fig 1: Topology Optimization Analysis [13]

\section{LITERATURE REVIEW}

A. Purushotham [1] presented in his work a stress and deflection analysis of a three wheeler passenger and load carrier chassis and modifying into one chassis for both types. Main focus of his work was to reduce the tooling cost and increasing the rate of production. To achieve this author performed a finite element analysis of the existing chassis of passenger vehicle. Software package used for this analysis was ANSYS. In existing analysis of passenger vehicle chassis under the static loading, values of stress and deflection were checked. Author also performed analysis of existing load carrier chassis under GVW and $50 \%$ overload condition and assessed the values of stress and deflection. 
An attempt was made to modify the chassis to make only one chassis for both types with simple modifications to reduce the tooling cost. Comparison of the results showed lesser values of stress and deflection for modified chassis.

S. S. Sane, Ghanshyam Jadhav, Anandraj H. [2] performed stress analysis of a light commercial vehicle chassis by using finite element method. Initially analysis of the existing chassis of the vehicle was performed and values of the stress and deflection were obtained. A total of nine different load cases were considered for the analysis of the chassis. To reduce the stress values stiffeners of varying height were added at the critical locations. The chassis was analyzed by finite element method using Altair HyperWorks software package. Comparison of the results showed that stresses on the critical location were reduced up to $44 \%$ by addition of stiffener.

Mohd. Azizi Muhammad Nor, Helmi Rashid, Wan Mohd Faizul Wan Mahyuddin, Mohd Azuan Mohd Azlan, Jamaluddin Mahmud [3] Using finite element modelling, simulation and analysis of low loader chassis is carried out and comparison of the results of the chassis was done with reinforcement and original chassis consisting of I-beams design application of 35 tons trailer. Finite element modeling (FEM), simulations and analysis was performed using a modeling software i.e. CATIA V5. Stress and displacement contour were later constructed and the maximum deflection and stress were determined by performing stress analysis. Computed results were then compared to analytical calculation, where it was found that the location of maximum deflection agrees well with theoretical approximation but varies on the magnitude aspect.

Tushar M. Patel, Dr. M. G. Bhatt, Harshad K. Patel, [4] did a study of the stress developed in chassis and deformation of chassis frame of Eicher 11.10 in Ansys and compared with mathematical calculations. The author did the study of the stresses developed in chassis and deformation of chassis frame of EICHER 11.10. The stress and deformation were calculated for the chassis frame and the finite element analysis was performed for the validation on the chassis frame model. The model of the chassis was developed in solid works 2009 and static structural analysis was done in ANSYS workbench. It was observed that the generated shear stresses were less than the permissible value so the design was considered safe.

Hemant B. Patil, Sharad D. Kachave, Eknath R. Deore, [5] performed stress analysis of ladder type low loader truck chassis with varying thickness of side member. Model used for the analysis was of Eicher 10.75. Basic calculations for the chassis frame were done by using simple bending theory and maximum values of stress and deflection were found out. In order to reduce the stress at critical points, a study was made in which five different cases were considered. Out of five cases in first three cases thickness of the side member were varied. In fourth case position of the cross member was changed and in the last case thickness of the cross member was changed. Static structural analysis was performed and results of all cases were compared with the analytical calculations. Value of maximum deflection agrees well with the theoretical value but varies on the magnitude aspect. Through the study the author concluded that changing the thickness of the cross member is better than changing the thickness of the side member.

Patel Vijaykumar V., Prof. R. I. Patel [6] focused their work towards weight reduction of chassis by performing structural analysis. Basic calculations for the chassis frame were done analytically based on the bending theory and values of stress and deflection were obtained. Finite element analysis for the existing chassis was performed for overload condition and stress and deflection values were obtained. For weight reduction design modifications were made by doing a sensitivity analysis. In sensitivity analysis section modulus and flange width were kept constant. Three cases were considered for weight reduction in which thickness and height of the flange were varied. Comparison of the results showed that out of three cases third case resulted in weight reduction of about $7 \%$ and stress and deflection values were reduced by about $12 \%$ and $11 \%$ respectively.

Sandip Godse, Prof. D. A. Patel [7] performed a static load analysis of TATA Ace Ex Chassis using ANSYS Workbench. In their work the authors performed static analysis of the existing chassis of the vehicle and found out the maximum value of stress and deflection. Author performed optimization exercise by the method of reinforcement techniques to reduce the value of stresses and increase the payload. After addition of reinforcements static analysis was performed and it was found that the stress values were reduced by about $38 \%$ thus increasing the payload of the chassis. Thus the author concludes that the modification made by optimization of the chassis through reinforcement techniques the chassis is capable of carrying loads beyond previous payload.

Dr. S. B. Rane, Harshal Shirodkar, P. Sridhar Reddy, [8] did their work in the use of optimization techniques for redesign of the forklift chassis by the use of finite element analysis. Author focused their work on the study of the optimum material distribution to get an idea of the load flow path based on which new design with higher strength to weight ratio as compared with original design could be obtained. Assembly fitment parameters/functional requirements were to be kept as it is. Methodology used by the author for structural optimization was in three phases. In first phase chassis was subjected to topology optimization to obtain optimum density plots to reduce its weight. In second phase after topology optimization, size optimization is performed to obtain the optimal thickness of all the structural members. Finally the output model is run for remaining load cases in the third phase. Author concludes how optimization techniques can be used as a tool in finite element analysis for achieving weight reduction. Through optimization techniques weight of the chassis was reduced by around $14.5 \%$. 
Hirak Patel, Khushbu C. Panchal, Chetan S. Jadhav, [9] carried out a sensitivity analysis for weight reduction of different cross-sections of truck chassis. The important criteria for the analysis of the chassis were maximum stress, maximum equilateral stress and deflection. The author performed his work towards the optimization of the automotive chassis for which a proper finite element model of the chassis was developed in PRO-E and finite element analysis was carried out using the ANSYS Workbench. The truck chassis analysis design was done analytically and the weight optimization was done by sensitivity analysis and a $17 \%$ weight reduction was achieved

Marco Cavazzuti, Dario Costi et al. [10] performed topology optimization on the automotive chassis and comparison was made between spider and coupe type of chassis. In their work the authors explains the setup of the optimization process, domain of optimization and the performance targets set to perform optimization. Finite element analysis and optimization was performed on the chassis model using Altair HyperMesh 10.0 and OptiStruct solver. With the help of topology optimization as a tool for weight reduction authors explains its effectiveness to find an optimum draft design for chassis. Author concludes that the process of design and analysis aided by collaborative optimization techniques can lead to innovative and more efficient solutions.

P. K. Sharma et al. [11] performed a stress analysis study of TATA Turbo Truck SE 1613. In the study finite element analysis was used in analyzing the chassis and author also explains its importance in minimizing the number of physical tests. For analysis model of Tata truck chassis is used. Analytical calculations were done for the overload condition of the chassis and the maximum values of the deflection and shear stress were obtained. Calculations were done for main section as well as its supporting section. Analytical stress and deflection values for the chassis were compared virtually by performing finite element analysis in ANSYS software package. Results showed that analytical values of stress and deflection agreed well with finite element analysis results.

S. Prabhakaran et al. [12] focused their work towards weight reduction of chassis by performing structural analysis. Basic calculations for the chassis frame were done analytically based on the bending theory and values of stress and deflection were obtained. Finite element analysis for the existing chassis was performed for overload condition and stress and deflection values were obtained. For weight reduction design modifications were made by doing a sensitivity analysis. In sensitivity analysis section modulus and flange width were kept constant. Three cases were considered for weight reduction in which thickness and height of the flange were varied. Comparison of the results showed that out of three cases third case resulted in about $6.7 \%$ of weight reduction.
Marco Cavazzuti et al. [13] focused their study on weight reduction of the automotive chassis by using structural optimization method linked with finite element analysis. Various optimization techniques were explained. The methods were briefly introduced, and some applications were presented and discussed with the aim of showing their potential. A particular focus was given to weight reduction in automotive chassis design applications. The author provided a quick overview on structural optimization methods. Author explained how topology and topometry optimizations were more suitable for an early development stage, whose outcome could be further refined through size and shape optimizations.

\section{SUMMARY}

In this paper a review of static analysis is presented. In the survey it is observed that most of the researchers have made use of finite element analysis for the stress analysis of chassis. Various weight reduction techniques are used for chassis by the researchers which are very much helpful in reducing the excess weight of the chassis.

It is observed that in most of the research work done on the chassis mostly linear static type of analysis is used for the analysis. Other types of analysis like non-linear, fatigue, crash, etc. must also be studied for making the chassis safer in strength.

\section{ACKNOWLEDGEMENTS}

I wish to express my gratitude and sincere thanks to my project guide Prof. R.V. Patil whose guidance, support and encouragement have helped me in completing this project work.

\section{REFERENCES}

[1]. A Purushotham, "Static Stress and Deflection Analysis of a Three Wheeler Chassis" International Journal of Engineering Science and Technology, Volume 5, 2013, pp. 1016-1024

[2]. S. S. Sane, Ghanashyam Jadhav, Anandraj H., "Stress Analysis of a Light Commercial Vehicle Chassis by FEM" Piaggio Vehicles, HTC 08, pp.1-5

[3]. Mohd. Azizi Muhammad Nor, Helmi Rashid, Wan Mohd Faizul Wan Mahyuddin, Mohd Azuan Mohd Azlan, Jamaluddin Mahmud, "Stress Analysis of a Low Loader Chassis" Procedia Engineering, 2012, 41, pp. 995-1001

[4]. Tushar M. Patel, Dr. M. G. Bhatt, Harshad K. Patel, "Analysis and Validation of Eicher 11.10 chassis frame using Ansys" International Journal of Emerging Trends and Technology in Computer Science ISSN: 2278 - 6856, Volume-2, Issue-2, March-April 2013

[5]. Hemant B. Patil, Sharad D. Kachave, Eknath R. Deore, "Stress Analysis of Automotive Chassis with Various Thicknesses" IOSR Journal of Mechanical and Civil Engineering ISSN: 2278-1684, Volume-6, Issue 1, MarchApril 2013, pp. 44-49

[6]. Patel Vijaykumar V., Prof. R. I. Patel, "Structural Analysis of Automotive Chassis Frame and Design 
Modification for Weight Reduction" International Journal of Engineering Research and Technology ISSN: 2278-0181, Volume-1, Issue-3, May 2012, pp. 1-6

[7]. Sandip Godse, Prof. D. A. Patel, "Static Load Analysis of Tata Ace Ex Chassis and Stress Optimization Using Reinforcement Technique" International Journal of Engineering Trends and Technology, Volume-4, Issue-7, July-2013, pp. 3037-3039

[8]. Dr. S. B. Rane, Harshal Shirodkar, P. Sridhar Reddy, "Finite Element Analysis and Optimization of an Forklift Chassis" Voltas Material Handling, Altair Technology Conference, Volume-1, 2013, pp. 1-6

[9]. Hirak Patel, Khushbu C. Panchal, Chetan S. Jadhav, "Structural Analysis of Truck Chassis Frame and Design Optimization for Weight Reduction" International Journal of Engineering and Advanced Technology ISSN: 2249 - 8958, volume-2, Issue-4,2013

[10]. Marco Cavazutti, Dario Costi, Andrea Baldini, Patrizio Moruzzi, "Automotive Chassis Topology Optimization: A comparison Between Spider and Coupe Designs" Proceedings of the world Congress on Engineering, 2011, 3, pp. 1-5

[11]. P. K. Sharma, Nilesh J. Parekh, Darshit Nayak, "Optimization and Stress Analysis of Chassis in TATA Turbo Truck SE1613" International Journal of Engineering and Advanced Technology, ISSN: 2249-8958, Volume-3, Issue-3, February 2014, pp.

[12]. S. Prabakaran, K. Gunasekar, "Structural Analysis of Chassis Frame and Modification for Weight Reduction" International Journal of Engineering Sciences and Research Technology, ISSN: 2277-9655, Volume-3(5), pp. 595-600 [13]. Marco Cavazuuti, Luca Splendi, "Structural Optimization of Automotive Chassis: Theory,Setup,Design" Structural and Multidisciplinary Optimization, 2011 pp. 1-3 [14]. N. R. Hema Kumar, P. L. N. Prakasa Rao Patnaik, A text book on Automobile Chassis and Body Engineering, First Edition

[15]. Nitin S. Gokhale, Sanjay S. Deshpande, Sanjeev V. Bedekar, Anand N. Thite, "Practical finite Element Analysis" Finite to Infinite Publication, First Edition, 2008

\section{BIOGRAPHIES}

Mr. Aditya V. Sahasrabudhe, have completed my B.E. with distinction class from MMCOE, Pune, Maharashtra. Presently pursuing M.E. in Design Engineering from University of Pune.

E-mail id: sahasrabudhe.aditya @gmail.com

Prof. Rajesh V. Patil, he is an Assistant Professor at Department of Mechanical Engineering, Sinhgad Institute of Technology and Science, Pune

E-mail id: rvpatil_sits@sinhgad.edu 